\title{
O Orçamento da U nião, o planejamento urbano e o Estatuto da Cidade
}

\author{
OMAR Borges do Prado FILHO*
}

\begin{abstract}
R esumo: O presente trabalho tem por abjetivo relacionar o Orçamento Geral da União com o planejamento urbano e o Estatuto da Cidade, Lei 10.257/2001, de 10 de julho de 2001, visando mostrar as congruências e incongruências da "política de desenvolvimento urbano" praticada no contexto das intervencões ditadas pelo governo federal, por intermédio de diversos órgãos que se sobrepõem com essa finalidade.
\end{abstract}

Palavr as-chave: orçamento da União; Estatuto da Cidade; políticas de desenvolvimento urbano; participação popular.

\section{Introdução}

O Orçamento da União é um instrumento de regulação das receitas e gastos gestado no âmbito do Congresso $\mathrm{N}$ acional e tem, como uma de suas finalidades, a aplicação de recursos financeiros em projetos de desenvolvimento urbano. Neste texto, apresentamos uma abordagem da sua origem à sua implementação, enfocando al guns matizes que envolvem a fase de elaboração e especificamente sua utilização com critérios políticos e não-oriundos de um planejamento e de uma priorização técnica ou diretiva de ações saneadoras dos imensos problemas urbanos existentes.

R elativamente à questão de planejamento urbano, o Brasil carece de uma política de desenvolvimento urbano, pois o que se vê são projetos isolados de intervenção na área de saneamento, habitação e infra-estrutura urbana, sem contudo explicitarem uma macrodiretriz traçada de forma a contextual izar a problemática existente e as possíveis soluções, direciona-

\footnotetext{
* Pós-graduado em Engenharia Sanitária pela Coppe/UFRJ e especialista em políticas públicas pela UFG.
}

mentos de investimentos e canalizações de recursos. A I guns projetos têm impacto direto nos municípios e, com os recursos orçamentários da U nião, são executados e funcionam isoladamente como intervenções de política urbana, sem, entretanto, estar contidos no rol de instrumentos para tal. Longe disto, às vezes são moeda de barganha político-econômica encetada por atores com objetivos diversos das comunidades que clamam e anseiam por intervenções voltadas a resgatar a sua inclusão no meio espacial e econômico das cidades.

Já o Estatuto da Cidade, Lei 10.257/2001, é um instrumento legal com o objetivo maior de regulamentar e disciplinar o uso do solo urbano e a gestão democrática das cidades na aplicação de recursos nos aspectos de desenvolvimento e reordenamento urbano. Trata-se de um instrumento de regulação federal com o intuito de definir a intervenção no território municipal, capaz de ordenar a sua utilização e democratizar a gestão pública com dispositivos legais que, se bem utilizados, afastam-se do caráter tradicional vigente deintervenção e regulação dos princípios norteadores de políticas de desenvolvimento urbano. 


\section{O Orçamento da União}

O Orçamento da União é um dos instrumentos de gestão financeira da U nião e contém, de modo geral, a previsão de receitas e despesas da administração pública federal no período de um ano fiscal. É no orçamento que se consignam as previsões sobre como e em que programas e empreendimentos serão empregados prioritariamente os recursos da U nião naquele exercício fiscal, isto é, anualmente, de $1^{\circ}$ de janeiro a 31 de dezembro.

No Brasil, a adoção do orçamento como dispositivo legal de gestão dos recursos públicos ocorre, pela primeira vez, na Constituição imperial de 1824. De lá para cá, registra-se uma evolução de fatos que marcam a participação do Congresso Nacional na elaboração e no acompanhamento do orçamento, com períodos - os quais retratam a situação política do país naquele instante - de ef etiva participação e outros em que faz o papel de mera instância homologatória da proposta encaminhada pelo Executivo. A Constituição de 1988 instituiu novas regras para a elaboração orçamentária, destacando-se o direito do Congresso discutir e propor como serão aplicados os recursos federais, a partir do exame das propostas encaminhadas pelo Executivo e da apresentação de emendas parlamentares.

A ssim, hoje, o Poder Legislativo participa nas fases relacionadas à elaboração, à aprovação, à execução e ao controle do Orçamento da União, que é regulado por uma ampla gama de leis e decisões normativas. Sobre o disciplinamento legal, por ordem hierárquica, tem-se a Constituição Federal, A tos das Disposições Constitucionais Transitórias e a L ei 4.320/64 (ainda em vigor em razão da não-elaboração da lei complementar, determinada pelo artigo 165 , parágrafo $9^{\circ}$ da Constituição Federal de 1988). Sobre o disciplinamento normativo, tem-se 0 Regimento Comum do Congresso Nacional, 0 Regulamento Interno da Comissão M ista de Planos, Orçamentos Públicos e Fiscalização, as regras apresentadas pela LDO e o parecer preliminar, no qual são estabelecidos os parâmetros e critérios que orientarão os relatores na elaboração do projeto de lei orçamentária, a ser apresentado à sanção do presidente da R epública.
Com esse arcabouço, três instrumentos, elaborados em momentos distintos, regulam 0 processo de planejamento e alocação de recursos federais:

1) o Plano Plurianual (PPA): prevê as despesas com programas, obras e serviços decorrentes que durem mais de um ano. No primeiro ano de governo, o presidente deve propor as diretrizes, metas e objetivos que, após aprovação, terão vigência nos próximos três anos de sua gestão e no primeiro ano da gestão seguinte. As ações e programas de governo devem estar de acordo com as metas e prioridades estabelecidas pelo PPA, sob pena de crime de responsabilidade;

2) a L ei de Diretrizes Orçamentárias (LDO): a partir do PPA, define as metas e prioridades para 0 ano seguinte. A LDO determina também as regras sobre mudanças nas leis de impostos, finanças e de pessoal, além de estabelecer orientações para elaboração do orçamento anual;

3) a Lei Orçamentária A nual ( $L O A)$ : consiste no orçamento propriamente dito. Contém os programas, projetos e atividades que contemplam as metas e prioridades estabelecidas na LDO, juntamente com os recursos necessários para o seu cumprimento. Dessa forma, define as fontes de receita e autoriza as despesas públicas, expressas em valores, detalhando-as por órgãos do governo e por função.

Esses instrumentos são objetos de discussão, primeiramente, nos diversos órgãos do Executivo e, posteriormente, consolidados pelo M inistério de Planejamento e Orçamento e encaminhados, em tempos distintos, ao Congresso Nacional como uma proposta do Executivo. N o Congresso N acional, a Comissão M ista de Planos, Orçamentos Públicos e Fiscalização (CM POF) analisa, modifica e vota a proposta do Executivo e a encaminha para apreciação do plenário do Congresso, de onde essas novas propostas retornam ao Executivo para sanção do presidente da República, com ou sem vetos.

Concebidos para articularem entre si, o PPA, a LDO e a LOA distinguem-se quanto às suas funções, ao tempo de vigência, ao detalhe do planejamento e aos prazos e trâmites de suas elaborações. Em função do objetivo desse trabalho, a seqüência a ser descrita limita-se apenas 
à atuação dos parlamentares no que concerne à elaboração do projeto de lei orçamentária (LOA).

A Comissão M ista de Planos, Orçamentos Públicos eFiscalização (CM POF) do Congresso $N$ acional éa única definida constitucionalmente e é a maior do parlamento. Ela conta com um presidente, três vice-presidentes, um relator geral e até sete subcomissões temáticas permanentes, sob a coordenação, cada uma, de um relator setorial e seu adjunto. Compõe-se de 84 membros titulares, sendo 63 deputados e 21 senadores, indicados pelos líderes dos partidos ou blocos parlamentares. 0 número de vagas de cada partido ou bloco parlamentar é definido pela M esa do Congresso $\mathrm{N}$ acional segundo 0 critério de proporcionalidade partidária, o que faz, dessa forma, que os maiores partidos detenham o maior número de vagas na comissão e nas subcomissões.

A o chegar à comissão, o projeto de lei orçamentária é examinado pelo relator geral, que elabora o parecer preliminar, após ampla negociação com os líderes (informais) dos partidos que compõe a comissão. 0 parecer, entre outros aspectos, deve conter uma análise da proposta remetida pelo Executivo e fixar os prazos e os parâmetros que devem nortear a apresentação das emendas e a análise delas pelos relatores setoriais e adjuntos, além dos critérios para cancelamento dos recursos que constam na proposta original do Executivo. É esse cancelamento que define a margem de realocação de recursos pel os relatores e permite a apresentação de emendas pel os parlamentares (a chamada "bolsa de fontes" ou "banco de fontes"). Esses recursos, no seu total, nos últimos anos, têm correspondido a menos de $2 \%$ do total do orçamento. As emendas incidem sobre os recursos destinados a investimentos. Constitucionalmente, não podem ser apresentadas emendas que incidam sobre as transferências constitucionais para estados, municípios e Distrito Federal, serviços da dívida pública e dotações para pessoal e seus encargos, além de outras definidas na L DO, como as limitações de al terações de gastos que têm sido estendidas a três itens de despesas: as contrapartidas de crédito interno e externo, a reserva de contingência e os gastos custeados pela emissão de títul os da dívida pública. O bserve-se, entretanto, que o próprio orçamento não contém todos os recursos da União, estando excluídos, por exemplo, os recursos do FGTS, que contam com gestores próprios e instâncias/conselhos de regulação e normatização para a aplicação desses recursos.

Essa possibilidade de propor realocações de recursos através da apresentação de emendas faz com que cada vez mais um número maior de parlamentares se interesse a tornarse membro da comissão e, se possível, ocupar os cargos de maior importância (como as relatorias) devido ao controle que exercem sobre o processo.

0 processo de escolha dos membros da comissão envolve uma complexa e intrincada negociação, é marcado por pressões, acordos, compromissos e trocas de favores e opera como uma forma de retribui ção aos parlamentares que apóiam a liderança e um meio de consolidação da posição do parlamentar escolhido. Dessa forma, conforme cita Bezerra, "as maiores bancadas e aquel as que sustentam as lideranças têm maiores chances de ter seus parlamentares indicados para integrar a CM POF. Esse peso das bancadas na definição dos membros da Comissão mostra a importância dos estados no interior dos partidos. Neste caso, é como se o partido fosse englobado pela bancada estadual" (Bezerra, 1999, p. 67). V ê-se, portanto, que a participação parlamentar na CM POF revestese de muita importância para o parlamentar propriamente dito, para seu estado de origem e para seu partido, pois constitui-se em uma chance de carrear recursos federais para obras e empreendimentos, além de servir politicamente como uma forma de consolidação e marca de presença em suas bases de apoio e até mesmo para utilizações outras, como apurado pela Comissão Parlamentar M ista de Inquérito sobre o Orçamento (CPM I) em 1993/94, que redundou na cassação de parlamentares por utilização e apropriação indevida de recursos da U nião que deveriam atender a projetos e empreendimentos.

Conforme B ezerra, "as razões que levam os parlamentares a se empenhar para participar da Comissão não são idênticas. 0 que se percebe é que diferentes concepções a respeito do orçamento e distintos interesses concorrem 
e conjugam-se durante a elaboração do projeto de lei orçamentária no Congresso" (idem, ibidem). Continuando, 0 autor cita o depoimento do deputado Cid Carvalho à CPMI do Congresso em 4/11/93: "Quer dizer, podemos considerar, pelo menos por hipótese, que pertencer à Comissão era não somente prestígio, mas também um meio de se atender a interesses próprios e a interesses de terceiros. Diria assim, nobre Relator: a idéia geral era que dentro da Comissão a pessoa defendia melhor os seus interesses eleitorais". Corroborando ainda mais essa questão, o mesmo autor ainda cita a resposta dada por J osé Carlos A Ives dos Santos aos membros da CPM I, ao ser interrogado sobre os motivos que a seu ver levavam os parlamentares a se tornarem membros da Comissão: "Sra. Deputada, só pode ser presunção tentar responder isso, só posso imaginar. U ma resposta dessa é subjetiva. A cho que a maior parte da Comissão queria defender interesses de suas regiões, de seus eleitores, de suas cidades, de seus municípios ou estados. Creio nisso com absoluta convicção. O utros não. Outros teriam interesse ou em levar vantagem sobre os outros, ter mais emendas aprovadas, até com o objetivo de beneficiar suas próprias regiões etc. $M$ as a Comissão de Orçamento dava poder, força, uma porção de coisas desse tipo, claro" (J osé Carlos A Ives dos Santos, CPM I do Orçamento, 20/10/ 93, p. 129).

E sses trechos pinçados obj etivam reforçar, em primeiro lugar, a importância conferida pelo parlamentar a sua participação na CM POF do Congresso Nacional e, em segundo lugar, os interesses variados que cercam a apresentação das emendas ao orçamento, que vão desde atender compromissos eleitorais com as suas bases políticas até interesses outros como 0 atendimento a lobbys, a escritórios de consultoria, a empreiteiros etc. Esses temas são adequadamente explorados por B ezerra (1999).

U ma outra questão, entretanto, que se apresenta é que todos os parlamentares têm 0 direito de propor emendas e, para isso, desde 1994 implantaram-se informal mente as designadas cotas individuais, que consistem em uma parcela de recursos idêntica reservada para cada parlamentar apresentar suas emendas ao orçamento. A s emendas que têm por objetivo
0 atendimento a programas e empreendimentos nos estados e municípios aos quais os parlamentares estão politicamente vinculados são designadas comumente como emendas paroquiais e visam aos interesses das bases eleitorais dos parlamentares. A inserção dessas emendas ditas paroquiais contribui para a pulverização dos recursos públicos, ou seja, a distribuição por inúmeras obras de parcelas de recursos que muitas vezes mostram-se insuficientes e que levam a um quadro de obras inacabadas, com prioridades discutíveis ou ao atendimento apenas parcial de uma prioridade latente. Esse quadro, conforme B ezerra (1999), configura a "transformação do capital econômico em capital político".

A apresentação de emendas por parte dos parlamentares não garante por si só que elas sejam contempladas no orçamento, podendo ser rejeitadas pelos relatores ou ter seu valor reduzido. Isto leva a um cenário de intensa negociação e intermediação no âmbito do Congresso Nacional.

Sancionada a Lei Orçamentária, começase outra romaria, desta vez junto aos órgãos da administração federal e ministérios para a liberação e execução do orçamento. Entram em jogo aspectos políticos e de interesses para liberação das emendas individuais ou da dotação global dos ministérios, além dos aspectos relacionados à própria burocracia da máquina governamental.

Conforme B ezerra,

M uitas emendas, como se sabe, são vetadas pelo presidente da R epública ou não chegam a ser executadas pelos órgãos ministeriais. M esmo quando os municípios recebem os recursos, as obras podem não ser finalizadas. As verbas repassadas pelo governo federal podem ser insuficientes para a execução das obras, ou, ainda, soma-se a isto o fato dos recursos serem apropriados indevidamente por pessoas e empresas envolvidas na execução das obras. M as se os recursos insuficientes ou a não-finalização das obras aparecem como medidas irracionais do ponto de vista administrativo, el as ganham sentido se referidas às relações políticas que as sustentam. Lançar a "pedra fundamental" é um passo no sentido de ganho de prestígio 
político. Considerar essas medidas do ponto de vista da concepção sobre a representação política em jogo, da importância política e interesses econômicos relacionados às obras e dos compromissos do parlamentar em relação à sua rede política permite apreender essas medidas em sua positividade. M as observe-se ainda que a obra inconclusa pode ser funcional ao político de uma outra forma. E m vista do interesse em ter a obra finalizada, a população, lideranças políticas e o prefeito podem se ver diante do dilema de ter que reeleger 0 candidato para assegurar a sua continuidade. Essa associação, portanto, seria uma forma de buscar o apoio de eleitores e lideranças transformando a finalização da obra numa proposta de campanha. (Idem, ibidem, p. 128)

V ê-se, portanto, que, em toda a luta pela apresentação de emendas ao orçamento e por toda a luta empreendida por sua liberação e execução, destacam-se aspectos políticos, de interesses, de representatividade, eleitoreiros, paroquiais etc. Não se falou, entretanto, de aspectos relacionados a uma política pública urbana, de aspectos técnicos indicativos de prioridades, de aspectos econômicos que levem à escolha de uma melhor alternativa e nem de um planejamento que considere as potencialidades e os problemas que envolvem as cidades no contexto campo-urbano-regional.

$\mathrm{N}$ ada disto, ao que parece, permeia o centro das atenções e preocupações dos parlamentares ao propor e lutar por suas emendas. 0 orçamento, na forma discorrida, é uma peça eminentemente política.

\section{Políticas de desenvolvimento urbano}

A evolução da rede urbana no Brasil pode ser dividida em dois períodos distintos. 0 primeiro período, de 1930 a 1980, de concentração acelerada da população em cidades, com a formação e ampliação de metrópoles complexas e de rede abrangente de núcleos urbanos. O segundo período, pós-1980, de redução no ritmo de crescimento urbano, especial mente das grandes cidades, porém com o crescimento de pequenas cidades com até dez mil habitantes.
0 quadro a seguir mostra o crescimento da população urbana no B rasil:

$\begin{array}{cc}\text { Ano } & \text { \% População urbana } \\ 1900 & 9,40 \\ 1920 & 10,70 \\ 1940 & 31,24 \\ 1950 & 36,16 \\ 1960 & 44,93 \\ 1970 & 55,92 \\ 1980 & 67,59 \\ 1990 & 75,59 \\ 2000 & 81,23\end{array}$

Fonte: Instituto Brasileiro de Geografia e Estatística (IBGE)

A Iguns determinantes importantes da evolução do processo de urbanização acentuada que se observa no período de 1940 a 1970 foram a industrialização, as mudanças na estrutura ocupacional da população rural, a agroindustrialização, a descentralização fiscal e de serviços públicos para os municípios e o emprego público, dentre outros. Na década de 1970, houve forte concentração no espaço territorial da atividade econômica, particularmente da indústria, fazendo com que a distribuição da expansão da população a seguisse, observandose, assim, o grande crescimento populacional nas regiões metropolitanas e nos centros urbanos maiores.

Conforme cita M otta et al.,

a dinâmica ea distribuição espacial da atividade econômica constituíram elementos de atração migratória. Há que se considerar, também, os fatores de expulsão, cujo papel na década de 70 foi fundamental. N esse período, em adição às secas, à dinâmica demográfica eà miséria no Nordeste, tivemos os impactos do processo de modernização conservadora na agricultura - modernização sem reforma agrária prévia -, responsável pela liberação de enorme contingente de trabalhadores rurais nas principais zonas agrícolas do Centro-Sul. Parte desse contigente deslocou-se às áreas de fronteira agrícola, notadamente à A mazônia, mas a grande maioria se dirigiu às cidades, que então pareciam oferecer enormes oportunidades. Esse movimento de população atingiu não só os grandes centros urbanos do Centro-Sul, mas também as regiões metropolitanas e as cidades maiores do Nordeste, que experimentaram 
rápida expansão industrial, fruto das políticas de incentivos fiscais e de empreendimentos estimulados e orientados pelo II PND. (M otta et al., 1997, p. 14)

A s citadas expansões urbanas também ocorreram em cidades do N orte, principalmente B elém e $M$ anaus.

No período de 1980 a 1991, observa-se queda na taxa de crescimento da população das cidades, de 5,2\% ao ano, na década de 1970 , para 2,5\% ao ano, no período 1980-1991. 0 aumento de 25 milhões de pessoas, em termos absolutos, ainda é muito significativo, porém aponta para uma desacel eração no crescimento urbano e um processo de periferização do crescimento das regiões metropolitanas, com conseqüente crescimento das cidades do entorno dessas regiões e de cidades de porte médio e pequenas. ${ }^{1}$

Alguns aspectos podem ser relacionados com esse quadro, em especial a evolução da economia no período, que levou à desconcentração geográfica da produção e à crise dos anos 80.0 caso da região metropolitana de São Paulo é emblemático por ter evidenciado forte desconcentração industrial para o interior ou mesmo para fora do estado. A crise dos anos 80 trouxe, também, redução no movimento migratório, denotando até mesmo migração de retorno. Além desse aspecto, ocorreram, igualmente, queda da fecundidade da população brasileira e a expansão da fronteira agrícola e de outras atividades, com o surgimento ou crescimento de novos núcleos interioranos de apoio. $^{2}$

Esse quadro do crescimento e redistribuição populacional urbana traz grande desafio à gestão urbana, à realocação de recursos para investimentos e à definição de prioridades com planejamento e estratégias de alcance urbanoregional. Citando M otta et al., "No contexto intra-urbano, embora existam problemas de extrema relevância relacionados ao financiamento do desenvolvimento urbano, há uma outra

1. 0 artigo de Motta et al., 1997, apresenta um estudo das evoluções e migrações populacionais ocorridas no período de 1930 a 1991.

2. Para uma análise do processo migratório, ver Motta et al., 1997. ordem de problemas, geralmente associados à falta ou à inadequação de políticas e instrumentos, que permitam melhor orientação do desenvolvimento urbano" (idem, ibidem, p. 23).

Nesse contexto, há de se perguntar: existem, atualmente, políticas e instrumentos para o desenvolvimento urbano? Antes de se deter neste questionamento, é mister fazer um breve histórico das políticas urbanas nacionais.

A questão afeta à política urbana ganhou ênfase, no B rasil, após a década de 1960 e tinha o Estado como seu principal articulador e ator. Era de cunho tecnoburocrática e acadêmica. Esteve relacionada às políticas regionais definidas nos planos nacionais surgidos no período da ditadura, com características marcantes de política compensatória.

A ssim, tem-se:

- no Plano Trienal (1963-1965), as cidades apareciam como "grandes coletividades" e havia o registro de problemas afins, como a urbanização decorrente da industrial ização, da pobreza e das precárias condições de vida, el evação da renda e sua eqüitativa distribuição. Elaborado em meio à crise política, esse plano não foi assumido como plano de governo e não chegou a ser implementado; ${ }^{3}$

- no Plano de A ção E conômica do Governo (Paeg - 1964-1966), o espaço urbano estava embutido nas políticas de produtividade social (emprego e habitação), com a menção de que a política habitacional deveria fazer parte de uma política de planejamento urbanístico e de desenvolvimento regional (não-formulada) e previuse a assistência a estados e municípios para elaborarem planos urbanísticos, além de outras referências nos capítulos das Diretrizes A grícolas, de Saúde e de Saneamento; 4

- no Plano Decenal (1967-1976), dedicouse um capítul o à temática urbana, definindo as bases de uma política nacional urbana e descaracterizando a vinculação de política urbana da política setorial de habitação (que

3. Ver com mais detalhes em Steinberger, 1998, p. 21 e 22.

4. Idem, ibidem, p. 22. 
constava no capítulo Desenvolvimento Social): ${ }^{5}$

- no Plano Estratégico de Desenvolvimento (PED - 1968-1970), o espaço urbano foi incluído nas políticas de emprego e população, com enfoque na concentração demográfica enas migrações, com menção a uma política de desenvolvimento urbano integrado; 6

- nas M etas e Bases para a A ção de G overno (1970), um capítulo versava sobre desenvolvimento urbano e regional, com esparsas referências ao espaço urbano; ${ }^{7}$

- no I Plano Nacional de Desenvolvimento (1972-1974), idem, com menção à criação das regiões metropolitanas como uma medida para consolidar o desenvolvimento do C entro-Sul ea reorientação dos fluxos migratórios rurais-urbanos do CentroSul para o Nordeste e as áreas de fronteiras. $^{8}$

0 marco divisório que se tem como a primeira política urbana nacional veio com o II Plano Nacional de Desenvolvimento (II PND 1974), quando trouxe o item "Política de desenvolvimento urbano", com o capítulo "D esenvolvimento urbano: controle da poluição e preservação do meio ambiente". A qui, separou-se política urbana da política regional e consagrou-se como objetivo da política urbana a promoção de uma melhor estruturação do sistema urbano, com vistas à maior eficácia das funções exercidas pelas cidades e à elevação dos padrões de urbanização e qualidade de vida. Trazia em seu bojo a proposta de desconcentração das grandes cidades, com a implantação de regiões metropolitanas e a seleção de pólos secundários como núcleos de apoio ao processo de ocupação. Essa estratégia foi marcada pelo descasamento entre a política urbana al mejada ea política econômica praticada, pois, em razão do desmoronamento do "milagre econômico", fruto de sucessivas crises nacionais e interna-

\footnotetext{
5. Idem, ibidem, p. 22.

6. Idem, ibidem, p. 22 e 23

7. Idem, ibidem, p. 23.

8. Idem, ibidem, p. 23.
}

cionais, a condução da política econômica buscava um novo patamar de substituição de importações, com ênfase nos setores de bens de capital e insumos básicos, com nítido caráter reconcentrador em termos espaciais. ${ }^{9}$

Em seqüência, tivemos o III PND, que trazia como subsídio uma proposta de política urbana, que vigorou de 1980 a 1985, sem, no entanto, ser incorporada por ele, em virtude da edição de uma R esolução do Consel ho Nacional de Desenvolvimento U rbano (CNDU). A razão do choque entre a Resolução do CNDU e o III PND foi que este último trazia embutido em suas propostas a crise mundial vivenciada no período, com redução dos gastos públicos e cortes de investimentos em habitação, transporte e saneamento, com queda nos níveis de bem-estar. Já a Resolução do CNDU tinha como estratégia a desconcentração e pregava, entre outros, 0 aumento da qualidade de vida urbana via melhoria das condições habitacionais, de transporte urbano e de saneamento básico. ${ }^{10}$

Uma marca inequívoca dessas propostas de políticas urbanas adotadas pel as cidades nos anos 70 e início dos anos 80 foram a excessiva centralização do papel do Estado nas mãos do Poder Executivo da União - uma prática da ditadura militar que, à época, acreditava na capacidade do Estado em investir e financiar todas as carências nacionais, entre elas 0 desenvolvimento urbano - eum viés nitidamente compensatório em conseqüência da situação vigente das condições de nossas cidades e do próprio interesse político do momento. Essa visão perdeu fôlego, não apenas pelo processo de redemocratização no início dos anos 80, mas, também, pela crise fiscal do Estado, com perda evidente da capacidade de investimentos e financiamentos públicos.

0 advento da Constituinte de 1988 mudou o entendimento da temática urbana, que passou a ser descentralizada, com a U nião mantendo a competência para instituir diretrizes de desenvolvimento urbano, enquanto a atribuição de executar a política urbana passou para os municípios.

9. Idem, ibidem, p. 23 a 24.

10. Idem, ibidem, p. 25 e 26 . 
Observa-se, que no período pós-85, passou a existir um discurso oficial de política urbana. Entretanto, o caráter compensatório existente não só foi mantido, como mais ainda explorado, sendo confundido com a política social encetada pelos governos pós-ditadura, em seus respectivos tempos. Observa Steinberger:

[...] os investimentos da U nião sobre o espaço urbano no período pós-85 foram constantes e, em alguns momentos, até mais significativos, embora de forma atomizada por meio de ações setoriais, [...] 0 aumento de recursos destinados ao espaço urbano, na década de 80 , deveu-se à presença marcante de organismos de cooperação técnica e financeira internacional, como o Banco M undial. A lém disso, a proliferação de movimentos sociais urbanos e de organizações não-governamentais, atores que passaram a exercer pressão sobre o Estado, também pode ser alinhada como fator explicativo do crescimento do volume desses recursos. Toda essa atuação visava a melhorar os indicadores de qualidade de vida, 0 que, de fato, poderia ser obtido via políticas setoriais e globais, prescindindo de uma política urbana. E foi 0 que aconteceu. (Steinberger, 1998, p. 27)

Hoje, na estrutura do governo federal, temse alguns ministérios, como a Secretaria Especial de Desenvolvimento U rbano da Presidência da República, o M inistério da Integração Nacional, o M inistério da Saúde, o M inistério do M eio A mbiente, o M inistério da Fazenda e o M inistério do Planejamento e Orçamento, que contam com programas, projetos e estudos relacionados à temática desenvolvimento urbano, sem contudo, haver um órgão que, de fato, centralize e coordene a política de desenvolvimento urbano, na forma ditada pela Constituição Federal. Conforme Steinberger, "as políticas setoriais e globais substituem uma política urbana" (idem, ibidem).

Essa não-formulação de macrodiretrizes e de políticas urbanas é um campo fértil para que interesses prevaleçam e façam com que recursos públicos, como os do Orçamento da U nião, sejam utilizados ao sabor e interesses outros que não os consentâneos com uma política definida e traçada por objetivos que visem ao alcance da melhoria de condições de vida e de desenvolvimento da população, caracterizando 0 assistencialismo e as trocas de favores.

\section{Estatuto da Cidade}

No contexto atual de privatizações dos serviços públicos, do desmonte da máquina estatal e corte nos gastos sociais, tem-se a necessidade de construção de uma nova ordem urbanística, redistributiva e includente. Somase à falta de investimentos para o desenvolvimento urbano uma outra ordem de problemas associados à falta ou à inadequação de políticas e instrumentos que permitam um redirecionamento das intervenções observadas no cotidiano das cidades.

A grande e acelerada urbanização das cidades, conjugada com as dificuldades impostas por sucessivas crises econômicas que o país vem experimentando, levou a uma favelização da população mais pobre, com o crescimento de favelas, mocambos, alagados e loteamentos clandestinos, em contraste com a exploração imobiliária e a concentração das áreas mais centrais e providas de infra-estrutura nas mãos de especuladores. Esse quadro perverso torna os investimentos em infra-estrutura, transportes e equipamentos públicos e de lazer mais caros, difíceis e inatingíveis por uma população mais pobre e carente, levando e acentuando a pobreza e a exclusão de parcelas significativas da sociedade aos benefícios sociais esperados de uma cidade.

0 Estatuto da Cidade é um instrumento que regulamenta o capítulo de política urbana da Constituição Federal de 1988 - artigos 182 e 183. Ele define uma concepção de intervenção no território que se afasta do tradicional caráter tecnocrático que apenas aponta os usos ideais ou desejáveis para cada parte do território. Tratase, portanto, de um marco regulatório que traz em seu conteúdo instrumentos, com respaldo constitucional, quevisam realizar o planejamento urbano sob uma nova ótica. U ma ótica que busca a garantia do cumprimento da função social da cidade, da propriedade urbana e da participação da comunidade na gestão e na condução de suas políticas de desenvolvimento e planejamento urbanos. 
Os instrumentos que fazem parte do Estatuto da Cidade podem ser divididos em três conjuntos distintos:

- um conjunto de novos instrumentos legais, de natureza urbanística, voltados para induzir, mais do que normatizar, as formas de uso e ocupação do solo, podendose citar a outorga onerosa do direito de construir; o direito de superfície; a transferência do direito de construir; as operações urbanas consorciadas; 0 direito de preempção; o parcelamento, a edificação ou a utilização compulsórios; 0 imposto sobre a propriedade predial e territorial urbana progressivo no tempo, e a desapropriação para fins de reforma urbana;

- a ampliação das possibilidades de regularização das posses urbanas, citando os instrumentos legais, como direitos: à moradia; às cidades sustentáveis; ao usucapião especial de imóvel urbano; à concessão de uso especial para fins de moradia; à concessão de direito real de uso, e às zonas especiais de interesse social;

- uma nova estratégia que incorpora a idéia de participação direta do cidadão em processos decisórios sobre a gestão das cidades, criando fóruns de participação e discussão das problemáticas que envolvem o desenvolvimento das cidades.

Por ser 0 objetivo deste artigo, o enfoque se restringirá somente ao aspecto da participação do cidadão na gestão das cidades. A ssim, estão previstos instrumentos como conferências e consel hos de política urbana nos âmbitos nacional, estadual e municipal; audiências e consultas públicas, além da obrigatoriedade de implementação do orçamento participativo, do Estudo de Impacto de Vizinhança e de planos diretores. Esses instrumentos devem ser utilizados pelos municípios para abrir espaço para os interesses dos cidadãos em momentos de tomada de decisão a respeito de intervenções sobre 0 território.

Constitucionalmente, rebatem-seno município os mesmos instrumentos integrados para a elaboração do orçamento: o Plano Plurianual (PPA ); a Lei de Diretrizes Orçamentárias
(LDO), e a Lei Orçamentária A nual (LOA ). É na elaboração da $L O A$ que se tem demonstrado mais adequada a utilização do instrumento legal, previsto no Estatuto da Cidade, de implementação do orçamento participativo que visa à participação da população no processo de el aboração do orçamento municipal.

0 orçamento partici pativo procura contemplar:

- a descentral ização das discussões com a população, através da divisão do município em regiões;

- a elaboração de critérios de atendimento das demandas regionais;

- a el aboração dos critérios de participação da população;

- a definição das instâncias de participação e suas competências específicas (reuniões, plenárias, conselhos etc.).

Como os recursos são escassos, esse processo é marcado por conflitos e momentos de intensa negociação dos diversos interesses a ser atendidos. 0 papel preponderante do poder público é promover um processo organizado de escuta e debate em torno das diferentes opções e suas implicações para a cidade, viabilizando as escolhas e sua implementação. 0 sentido maior desse processo é ampliar a base de conhecimento, planejamento e sustentação da política urbana, que assim vai deixando de ser um assunto restrito aos especialistas - e de manobras de interesses - e passando a ser um patrimônio de toda a comunidade. Os pactos e acordos que são feitos, envolvendo a política e a gestão urbana, podem ter bases mais includentes e públicas, diferentemente do que historicamente vem sendo praticado.

0 conhecimento de todos aspectos que cercam a elaboração e a implementação do orçamento municipal é de relevada importância, pois a priorização e a consciência de uma mel hor utilização dos recursos envolvidos são o caminho para a redução dos imensos problemas de ordem urbanística observados na maioria das cidades.

Para se ter idéia do contexto dramático que envolve a elaboração e implementação do orçamento, no âmbito municipal, tem-se os 
seguintes limites orçamentários, impostos por ordem constitucional, a que se devem observar:

- a folha de pessoal deve atingir até $60 \%$ do orçamento;

- a transferência mínima para educação é de $25 \%$;

- a transferência mínima para saúde é de $10 \%$;

- a transferência para o Poder L egislativo é de até $7 \%$.

Note-se que, se o município praticar os limites acima descritos, ele já tem um déficit orçamentário de $2 \%$, sem contar inúmeros outros gastos que normal mente fazem parte da administração municipal, tais como as dívidas contraídas em conseqüência de empréstimos, os precatórios, a manutenção da máquina administrativa e de programas especiais etc.

Ganha relevância, mais do que nunca, a gestão municipal. 0 envolvimento e 0 acompanhamento da comunidade são vitais, não só para uma boa gestão da administração municipal, mas principalmente para a orientação dos investimentos num quadro de escassez como a realidade atual. A ssim, a priorização e o reordenamento dos recursos disponíveis na busca de uma otimização e al cance social maximizado devem ser o mote da participação popular e, hoje, encontra-se respaldo legal para isto, com a implementação dos dispositivos e instrumentos existentes no Estatuto da Cidade.

Como todo dispositivo legal, o Estatuto da Cidade não é diferente e, para que ele exerça a sua função, énecessário o engajamento da sociedade civil organizada e uma mudança de cultura política dos administradores, que devem praticar o bem comum acima de qual quer coisa e deixar 0 assistencialismo de interesses para exercitar a cidadania e o respeito à comunidade, na busca de soluções e práticas que el evem os benefícios sociais, a inclusão e o equacionamento das questões aflitivas vivenciadas em cada cidade.

Retomando o eixo deste artigo, frisa-se a questão dos investimentos orçamentários no desenvolvimento urbano, diante de um quadro de escassez de recursos, no qual ganham importância os recursos destinados a investimentos em empreendimentos de caráter urbano consignados no Orçamento da União. Esses recursos não-onerosos, em boa parte das situações, são um dos poucos com que contam os municípios para investimentos na área urbana, em habitação, infra-estrutura e equipamentos públicos e sociais. Portanto, são de muita importância e de grande benefício social, reforçando a necessidade de serem bem aplicados, geridos conforme as necessidades da comunidade, e de serem fruto de uma priorização ditada pela população local, pois, certamente, as carências são muito maiores que os recursos disponíveis. A participação popular deve ser exercitada para o correto direcionamento desses recursos.

$\mathrm{N}$ ão há incongruências no exercício político desses recursos, pois a negociação, o direcionamento e a destinação de prioridades de investimentos públicosé um jogo político exercido primeiramente na definição do orçamento participativo no âmbito municipal, depois no âmbito do Congresso Nacional, na definição do Orçamento da União e, por fim, na busca da realização dos investimentos nos diversos ministérios envolvidos. A diferença, porém, é que isto deve ser feito às claras, com a participação da população, prevalecendo, aí sim, a importância, o domínio dos grupos que estão no poder graças a uma regra democrática e, nesta seqüência, certamente serão avaliados nas urnas nos pleitos seguintes, perpetuando a democracia, a participação popular e a busca de uma sociedade mais justa, includente e de oportunidades de acesso a bens públicos a uma parcela maior de pessoas.

\section{Conclusão}

Por todo o exposto, algumas questões sobressaem-se:

- no quadro de carência de recursos, 0 Orçamento da União é uma fonte importante e vital para os municípios, capaz de empreender obras e intervenções no contexto campo-urbano de relevantes benefícios sociais e de desenvol vimento econômico;

- a intervenção política na distribuição dos recursos é uma prática corrente em vários países de democracia estabi lizada, portanto, ela em si não é um mal maior, a não ser 
quando oriunda de interesses outros que não 0 benefício às comunidades assistidas, ou quando são de prioridades ditadas por interesses de lobbys e empreiteiras, ou simplesmente quando se tem "a transformação do capital econômico em capital político"; - é importante, no entanto, não se restringir o papel do parlamentar à confecção de emendas, pois a prática do paroquialismo é um embuste que serve aos interesses de uma classe dominante que manipula e tenta se perpetuar no poder. A lém do mais, a atuação parlamentar reveste-se de importância ímpar ao discutir, fiscalizar e propor leis que levem o país ao rumo do desenvolvimento e à eqüidade social;

- falta ao país um projeto Brasil que dite de forma integrada e diretiva as ações a serem implementadas e, a partir do qual, decorram as intervenções que vão nortear 0 desenvolvimento urbano-regional e as aplicações de recursos. Não se tem concatenação entre os diversos órgãos federais na implementação das políticas e ações voltadas ao desenvolvimento urbano e sim projetos isolados;

- o Estatuto da Cidade é um importante instrumento de regulação e indução ao reordenamento e ao desenvolvimento urbano. Porém, como toda legislação, necessita de melhor divulgação, conscientizando a população quanto à sua utilidade e a seus benefícios, para não ser mais uma lei que "não pega", principalmente porque mexe com interesses fortes e enraizados na sociedade que buscam a especulação imobiliária e as benesses do poder público;

- os municípios, via de regra, não contam em suas estruturas com pessoal técnico capaz de planejar e pensar o desenvolvimento urbano e regional, com base na sua auto-sustentabilidade e realidade específica. Esse quadro está agravado com 0 atual contexto de política de desmonte do setor público, que expõe de forma visceral as estruturas públicas aos interesses econômicos que ditam, na maioria das vezes, as prioridades da forma que melhor lhes convêm.
Resta, assim, mais que nunca o exercício da cidadania, da consciência pública e da cobrança aos mandatários e representantes populares, para que se tenha o cumprimento das legislações, dos planos de governo, das promessas de campanha política e da aplicação dos recursos financeiros na busca do desenvolvimento econômico, urbano e social.

A bstract: The present work has for dojective makes list of the budget Union with urban planning and the Statue of City, law 10.257/2001 of July 10, 2001. On make list of this three subject, dbjective conclude of congruence and incongruent of "politic of urban development" practice on the context of intervention dictation for Federal Goverrment, for through of many institutions which put over with this punpose.

K ey-words: ladget of Union; Statue of City; politic urban of development; popular participation.

\section{R eferências}

A LM EIDA, M arco A ntônio de. Orçamento participativo. São Paulo: Dicas Instituto Pólis, GS N. 92, 1997.

BECKER, Bertha K. Reflexões sobre políticas de integração nacional e desenvolvimento regional. 2000.

BEZERRA, M arcos Otávio. Em nome das "bases". Rio deJ aneiro: Relume Dumará, 1999.

CY M BA LISTA, Renato. Estatuto da cidade. São Paulo: Dicas Instituto Pólis, n. 181, 2001.

M OTTA, Diana M .; M UELLER, Charles C.;TORRES, $M$ arcelo de 0 . A dimensão urbana do desenvolvimento econômico-espacial brasileiro - Texto para discussão n. 530. B rasília: I pea, 1997.

OLIVEIRA , Isabel Cristina E. E statuto da cidade: para compreender... Rio de J aneiro: Ibam/Duma, 2001.

ROL NIK, Raquel. Estatuto da cidade - guia para implementação pelos municípios e cidadãos. B rasília: Caixa/Instituto Pólis/Câmara dos D eputados, 2001.

STEINBER GER, M arilia. Por uma política urbanaregional. In: Sociedade e Estado. B rasília: U rbano / N ovos O Ihares Sociológicos, v. XIII, n. 1, 1998.

ReCEBido em DEZEMbro de 2002 A provado em JULHO de 2003 